This document is the accepted manuscript version of the following article:

Fu, Y. H., Zhao, H., Piao, S., Peaucelle, M., Peng, S., Zhou, G., ... Janssens, I. A. (2015). Declining global warming effects on the phenology of spring leaf unfolding. Nature, 526(7571), 104-107. https://doi.org/10.1038/nature15402

\title{
1 Declining global warming effects on the phenology of spring 2 leaf unfolding
}

3 Yongshuo $\mathrm{H} \mathrm{Fu}^{1,2}$, Hongfang Zhao ${ }^{1}$, Shilong Piao ${ }^{1,3,4}$, Marc Peaucelle ${ }^{5}$, Shushi Peng ${ }^{1,5}$, Guiyun $4 \quad$ Zhou $^{6}$, Philippe Ciais ${ }^{5}$, Mengtian Huang ${ }^{1}$, Annette Menzel ${ }^{7,8}$, Josep Peñuelas ${ }^{9,10}$, Yang Song ${ }^{11}$, Yann Vitasse ${ }^{12,13,14}$, Zhenzhong Zeng ${ }^{1}$, Ivan A Janssens ${ }^{2}$

${ }^{1}$ Sino-French Institute for Earth System Science, College of Urban and Environmental Sciences, Peking

8 University, Beijing 100871, China

$9{ }^{2}$ Centre of Excellence PLECO (Plant and Vegetation Ecology), Department of Biology, University of

10 Antwerp, Universiteitsplein 1, B-2610 Wilrijk, Belgium

$11{ }^{3}$ Key Laboratory of Alpine Ecology and Biodiversity, Institute of Tibetan Plateau Research, Chinese Academy

12 of Sciences, Beijing 100085, China

$13{ }^{4}$ Center for Excellence in Tibetan Earth Science, Chinese Academy of Sciences, Beijing 100085, China

$14{ }^{5}$ Laboratoire des Sciences du Climat et de l'Environnement, CEA CNRS UVSQ, Gif-sur-Yvette, France

$15{ }^{6}$ School of Resources and Environment, University of Electronic Science and Technology of China, Chengdu,

16 China

$17{ }^{7}$ Ecoclimatology, Technische Universität München, Freising, Germany

$18{ }^{8}$ Technische Universität München, Institute for Advanced Study, Lichtenbergstraße 2a, 85748 Garching,

19 Germany

$20 \quad{ }^{9}$ CREAF, Cerdanyola del Vallès, Barcelona 08193, Catalonia, Spain

${ }^{10}$ CSIC, Global Ecology Unit CREAF -CSIC-UAB, Cerdanyola del Vallès, Barcelona 11 08193, Catalonia,

Spain

$23{ }^{11}$ Department of Atmospheric Sciences, University of Illinois, Urbana, IL 61801, USA

$24{ }^{12}$ University of Neuchatel, Institute of Geography, Neuchatel, Switzerland

$25{ }^{13}$ WSL Swiss Federal Institute for Forest, Snow and Landscape Research, Neuchatel, Switzerland

$26{ }^{14}$ WSL Institute for Snow and Avalanche Research SLF, Group Mountain Ecosystems, Davos, Switzerland 
1 Earlier spring leaf unfolding is a frequently observed response of northern trees to climate 2 warming ${ }^{1,2,3,4}$. Many deciduous tree species require chilling for dormancy release, and 3 warming-related reductions in chilling may counteract the advance of leaf unfolding in 4 response to warming ${ }^{5,6}$. Empirical evidence for this, however, is limited to saplings or twigs 5 in climate-controlled chambers ${ }^{7,8}$. Using long-term in situ observations of leaf unfolding for 6 seven dominant European tree species at 1,245 sites, we show here that the apparent response of leaf unfolding to climate warming $\left(\mathrm{S}_{\mathrm{T}}\right.$, expressed in days advance per $\left.{ }^{\circ} \mathrm{C}\right)$ has significantly decreased from 1980 to 2013 in all monitored tree species. Averaged across all 9 species and sites, $S_{T}$ decreased by $40 \%$ from $4.0 \pm 1.8$ days ${ }^{\circ} \mathrm{C}^{-1}$ during $1980-1994$ to $2.3 \pm$ 1.6 days ${ }^{\circ} \mathrm{C}^{-1}$ during 1999-2013. The declining $S_{T}$ was also simulated by chilling-based phenology models, albeit with a weaker decline (24\%-30\%) than observed in situ. The reduction in $S_{T}$ is likely to be partly attributable to reduced chilling. Nonetheless, other mechanisms may also play a role, such as 'photoperiod limitation' mechanisms that may become ultimately limiting when leaf unfolding dates occur too early in the season. Our results provide empirical evidence for a declining $S_{T}$, but also suggest that the predicted strong winter warming in the future may further reduce $S_{T}$ and therefore result in a slowdown in the advance of tree spring phenology.

The phenology of spring leaf unfolding influences regional and hemispheric-scale carbon balances $^{2}$, the long-term distribution of tree species ${ }^{9}$, and plant-animal interactions ${ }^{10}$. Changes in the phenology of spring leaf unfolding can also exert biophysical feedbacks on climate by modifying the surface albedo and energy budget ${ }^{11,12}$. Recent studies have reported significant advances in spring phenology as a result of warming in most northern hemisphere regions ${ }^{1,3,4}$. Climate warming is projected to further increase ${ }^{13}$, but the future evolution of the phenology of spring leaf unfolding remains uncertain - in view of the imperfect understanding of how the underlying mechanisms respond to environmental stimuli ${ }^{12,14}$. In addition, the relative contributions of each environmental stimulus, which together define the apparent temperature sensitivity of the phenology of spring leaf unfolding (advances in days per degree Celsius warming, $\mathrm{S}_{\mathrm{T}}$ ), may also change over time $\mathrm{e}^{6,8,15}$. An improved characterization of the variation in 
1 phenological responses to spring temperature is thus valuable, provided that it addresses temporal

2 and spatial scales relevant for regional projections.

3 Numerous studies have reported advanced spring leaf unfolding which matches warming trends 4 over recent decades ${ }^{1,3,4}$. However, there is still debate regarding the linearity of leaf unfolding 5 response to the climate warming ${ }^{6,7}$. Recent experimental studies of warming using saplings have 6 shown that $\mathrm{S}_{\mathrm{T}}$ weakens as warming increases ${ }^{7}$. Experimental manipulation of temperature for 7 saplings or twigs, however, might elicit phenological responses that do not accurately reflect the 8 response of mature trees ${ }^{16,17}$. We therefore investigated the temporal changes in $\mathrm{S}_{\mathrm{T}}$ in adult trees 9 monitored in situ and exposed to real-world changes in temperature and other climate variables. 10 These long-term data series were obtained across Central Europe from the Pan European 11 Phenology Project (http://www.pep725.eu/). Data were collected from 1,245 sites for seven 12 dominant tree species (see methods and the distribution of the sites in Extended Data Fig. 1). The 13 aims of our analysis are to determine the temporal changes in $\mathrm{S}_{\mathrm{T}}$ at the species level during 1980142013 , a period during which Europe has substantially warmed ${ }^{13}$, and to relate these changes in $\mathrm{S}_{\mathrm{T}}$ to differences in other physiological and environmental factors.

17 For each species at each observation site, we first determined the preseason length as the period before leaf unfolding for which the partial correlation coefficient between leaf unfolding and air temperature was highest (see methods). We used a gridded climate dataset, including daily maximum and minimum air temperature, precipitation and absorbed downward solar radiation, with a spatial resolution of $0.25^{\circ}$ (approximately $\left.25 \mathrm{~km}\right)^{18}$. The optimal length of the preseason 22 ranged between 15 days and four months across the seven species (Extended Data Fig. 2), in agreement with earlier results ${ }^{1,14}$. We then calculated the average temperature during the preseason for each year at each site and calculated $\mathrm{S}_{\mathrm{T}}$ using ordinary least squares linear regression for the entire period and for two 15-year periods, namely 1980-1994 and 1999-2013, that had slight difference in preseason lengths (Extended Data Fig. 3a). The leaf unfolding dates were negatively correlated with the preseason temperature, with a mean linear correlation coefficient of $-0.61 \pm 0.16$, determined using the preseason defined from the time period 19802013. Almost all individual tree-level correlations were negative (99.7\%) and the vast majority of 
1 with previous studies ${ }^{1,4}$, the timing of leaf unfolding substantially advanced in all species for 2 1980-2013, with an average advancing rate of $3.4 \pm 1.2$ days ${ }^{\circ} \mathrm{C}^{-1}$ across all species-sites 3 (hereafter, a positive value indicates advancement) (Fig. 1a). But the surprising result is that $S_{T}$ 4 significantly decreased by $40.0 \%$ from $4.0 \pm 1.8$ days ${ }^{\circ} \mathrm{C}^{-1}$ during $1980-1994$ to $2.3 \pm 1.6$ days ${ }^{\circ} \mathrm{C}^{-}$ $5{ }^{1}$ during 1999-2013 $(t=-37.3, d f=5473, P<0.001)$ (Fig. 1b). All species show similar significant 6 decreases in $\mathrm{S}_{\mathrm{T}}$ (Fig. 1a), although the extent of reduction was species-specific. For example, 7 Aesculus hippocastanum (see caption to Fig. 1 for English common names) had the largest 8 decrease in $\mathrm{S}_{\mathrm{T}}\left(-2.0\right.$ days $\left.{ }^{\circ} \mathrm{C}^{-1}\right)$, while $\mathrm{S}_{\mathrm{T}}$ decreased only slightly (but still significantly) in Fagus 9 sylvatica $\left(-0.9\right.$ days $\left.{ }^{\circ} \mathrm{C}^{-1}\right)$ (Fig. 1a). Similar results were also obtained using a fixed preseason 10 length determined either in the time period 1980-1994 or in 1999-2013 (Extended Data Fig. 3b 11 and 3c). The declining $\mathrm{S}_{\mathrm{T}}$ could, however, also have been an artifact resulting from the 12 encroachment ${ }^{\star}$ of leaf unfolding dates into the preseason period that was used to calculate the temperature sensitivity. We therefore calculated the number of _encroachment days ${ }^{6}$ and found it 14 is very small compared to the pre-season length even in the warmest period (Extended Data Fig. $153 \mathrm{~d}$ and 3e). Because the time scale of the analysis could affect the estimates of $\mathrm{S}_{\mathrm{T}}{ }^{19}$, we also calculated $\mathrm{S}_{\mathrm{T}}$ using 10-year intervals (instead of 15 years) and found consistent results, i.e., $\mathrm{S}_{\mathrm{T}}$

17 significantly decreased between the 1980s and the last decade for all species except Tilia cordata 18 (Extended Data Fig. 5a). We further calculated $S_{\mathrm{T}}$ with a 15-year moving window from 1980 to 2013 and found a significant decrease $(P<0.01)$ for each of the seven species (Fig. 1c). $\mathrm{S}_{\mathrm{T}}$ decreased by an average of 0.7 days ${ }^{\circ} \mathrm{C}^{-1}$ per decade across all species. Similar results were also reached when a 10-year interval was used (Extended Data Fig. 6). These results suggest a significant change in the response of leaf unfolding to the ongoing climate warming in all studied tree species in Central Europe.

Since there is no single accepted theory to account for the decreased $\mathrm{S}_{\mathrm{T}}$ over the period 19802013, we propose three mutually non-exclusive hypotheses: (1) adaptation to increased variance in spring temperature, (2) photoperiodic limitations (due to earlier leaf unfolding) overriding temperature controls, and (3) reduced duration and/or sum of cold temperatures during dormancy, a lost chilling' mechanism. 
1 The first hypothesis relates to possible effects of an increased variance in temperature. A recent 2 study reported substantial spatial differences in $\mathrm{S}_{\mathrm{T}}$, with smaller absolute values at sites with a 3 higher variance of local spring temperature ${ }^{20}$. Trees may indeed develop conservative strategies 4 (or higher phenological plasticity) of spring leaf unfolding in places where temperature fluctuates 5 more, in order for instance to avoid spring frost damage ${ }^{21}$. The observed declining $\mathrm{S}_{\mathrm{T}}$ could 6 therefore partly result from an increase in the variance in spring temperature. However, the variance in spring temperature only significantly increased at sites of two species and decreased

8 for all the other species except Fraxinus excelsior (Fig. 2a). This suggests that increased variance 9 in spring temperature cannot account for the decreased $\mathrm{S}_{\mathrm{T}}$. We further studied the fluctuations in daily mean temperature and diurnal temperature amplitude $\left(T_{\max }-T_{\min }\right)$ over the preseason for the two periods 1980-1994 and 1999-2013, and for three groups of sites with comparable mean

12 annual temperature (MAT). The fluctuations in daily temperature and diurnal temperature amplitude during the preseason were similar during the two time periods between which $\mathrm{S}_{\mathrm{T}}$ declined (Extended Data Fig. 7), suggesting that altered temperature variability is not an obvious cause for the declining apparent temperature sensitivity of leaf unfolding.

17 Precocious leaf unfolding in warm springs may increase the risk of late frost events for trees ${ }^{21}$. To overcome this risk during warm springs, many species have evolved a protective mechanism related to photoperiod ${ }^{22}$, which hinders the warming response when days are still short and the risk for subsequent frost events is thus high. Our second, alternative, hypothesis to account for the observed decrease in $\mathrm{S}_{\mathrm{T}}$ in recent decades is therefore a change in the relationship between chilling accumulation and heat requirement, due to the shortening days as warming advances leaf unfolding. However, we did not observe changes in $\mathrm{S}_{\mathrm{T}}$ with latitude, neither across all species, nor for individual species (Extended Data Fig. 8), as one may expect if photoperiod was a strong co-limitation of leaf unfolding. Nonetheless, we have no evidence to exclude photoperiod as a controlling mechanism for the decline of $\mathrm{S}_{\mathrm{T}}$ since different populations may have different genetic adaptations to photoperiod ${ }^{23}$. In addition, the lack of relation between $\mathrm{S}_{\mathrm{T}}$ and latitude may have been because the response of spring phenology to photoperiod can be associated with many 29 confounding factors, such as tree age $^{17}$, successional niche ${ }^{23}$ (although there is some $30{\text { contradictory } \text { evidence }^{8} \text { ), } x y l e m \text { anatomy }}^{24}$, or chilling conditions ${ }^{8}$. We can therefore not 
4 The third hypothesis to explain for the decreased $\mathrm{S}_{\mathrm{T}}$ is based on the control of spring phenology

conclude that photoperiod did not influence $\mathrm{S}_{\mathrm{T}}$, but how it might directly or indirectly affect spring phenology still remains unclear and is currently under debate ${ }^{6,15,22}$.

by cold temperatures during the dormancy period. In general, temperate and boreal trees require a

certain amount of heat (heat requirement) after they come out of the rest period to initiate leaf unfolding in spring ${ }^{25}$. Logically, this heat requirement is met sooner during warmer springs, which explains the advance of leaf unfolding in response to global warming. The heat requirement, however, is negatively correlated with chilling ${ }^{7,8,25}$, i.e. the accumulation of cold temperatures during the dormancy period. Since the dormancy period warmed during the study period, the accumulated chilling is progressively reduced, thereby increasing heat requirement and slowing down the advance of leaf unfolding. The net effect of lost chilling can thus be a reduced $\mathrm{S}_{\mathrm{T}}$. This effect may be further exacerbated by the non-linearity of the negative correlation between the heat requirement and the chilling accumulation ${ }^{7,25}$.

To test this hypothesis, we calculated the accumulated chilling that was defined as the sum of days when daily air temperature was within the range between 0 and $5{ }^{\circ} \mathrm{C}$ from $1^{\text {st }}$ November in the year prior to leaf unfolding (see methods), and found a significant decrease $(P<0.001)$ in chilling accumulation for all species (Fig. 2b). Chilling accumulation was 10\% lower for 19992013 than for 1980-1994. Chilling accumulation was also significantly decreased with a 15-year moving window (Extended Data Fig. 9a) and when defined by different temperature thresholds (Extended Data Fig. 9b). To further test the importance of the lost chilling ' hypothesis, we applied three chilling-based phenology models to the data (See Supplementary information). All three models captured the declining $\mathrm{S}_{\mathrm{T}}$ after their calibration at each site and their integration with observed climate forcing, irrespective of species (Fig. 3). The modelled relative reductions in $\mathrm{S}_{\mathrm{T}}$ between the two periods 1980-1994 and 1999-2013 were, however, smaller than the observed decline, i.e. simulated $\mathrm{S}_{\mathrm{T}}$ was reduced by $28.8 \%, 24.4 \%$ and $30.4 \%$ for the Sequential, Parallel and Unified chilling-based models, respectively, whereas the observed $\mathrm{S}_{\mathrm{T}}$ was reduced by $40.0 \%$. This may suggest that either other protective or adaptive mechanisms, such as photoperiod or adaptation mechanisms, are affecting the decline in $\mathrm{S}_{\mathrm{T}}$, or that the three models do 
not completely accurately represent all chilling mechanisms. There are also uncertainties related to the $0.25^{\circ}$ gridded climate product that may not represent local air temperature at each site (snow effects, shading, slope, elevation). Furthermore, using the Unified model, we applied idealized stepwise increases of winter temperature over the period $1980-2013$ by $+1{ }^{\circ} \mathrm{C}$ to $+5^{\circ} \mathrm{C}$, and consistently obtained a decrease in $\mathrm{S}_{\mathrm{T}}$ induced by the loss of chilling in these idealized tests (Extended Data Fig. 9c). However, we did not find marked differences in $\mathrm{S}_{\mathrm{T}}$ between years with more chilling days and years with less chilling days (Extended Data Fig. 10a-c), which can probably be explained by the different climate conditions between years with more and less chilling days. For example, the relatively high spring radiation sum in years with less chilling days might buffer the effects of less chilling days (Extended Data Fig. 10d), and eventually resulted in a similar $\mathrm{S}_{\mathrm{T}}$, but this remains speculation. Clearly, further studies are needed to support these inferences and their role in the control over phenology. Overall, these results support the third hypothesis that the decline in chilling accumulation is, at least partly, driving the decline in $\mathrm{S}_{\mathrm{T}}$, although the possible constraint of photoperiod/radiation could not be excluded.

Changes in spring phenology associated with climate warming have direct impacts on regional and global carbon cycling ${ }^{12}$. Studies have reported that an extension of the growing season can increase the photosynthetic production of forests by $0.5-1 \%$ per day ${ }^{26,27,28}$. We found that the apparent sensitivity of spring phenology to warming for seven temperate tree species in Central Europe has declined significantly as winter and spring temperatures increased over the past three decades. These findings indicate that the early spring phenologically-driven increases in carbon uptake may slow down for temperate forests under future conditions of climate warming. On the other hand, the declining apparent temperature sensitivity of spring phenology may be beneficial for the trees. Extreme climatic events have dramatically increased in recent decades, especially warm winters and springs ${ }^{29}$, and the decreased apparent temperature sensitivity would thus reduce the risk of late spring frost damage by avoiding premature leaf unfolding.

\section{Methods}

Data sets. In situ phenological observations were obtained from the Pan European Phenology network (http://www.pep725.eu/), which provides an open European phenological database 
1 comprising multiple plant phenological records. We selected the records of leaf unfolding dates

2 for seven tree species at 1,245 sites for 1980-2013 from sites in an area stretching from north

3 Germany to the Adriatic Sea (see Extended Data Fig. 1). The leaf unfolding dates were defined

4 according to the $\mathrm{BBCH}$ code (Biologische Bundesanstalt, Bundessortenamt und Chemische

5 Industrie). Dates were excluded from the analysis when the trees flushed later than the end of

6 June. The daily mean air temperature of each site was derived from a gridded climate data set of

7 daily maximum and minimum temperature at $0.25^{\circ}$ spatial resolution (approximately $\left.25 \mathrm{~km}\right)^{18}$.

8 We also applied another climate forcing dataset (CRU-NCEP v5, with spatial resolution of $0.5^{\circ}$

9 and temporal resolution of $6 \mathrm{~h}$, http://dods.extra.cea.fr/data/p529viov/cruncep/), and returned very similar results (Extended Data Fig. 5c).

12 Analysis. The relevant period for leaf unfolding is several months prior to the phenological event $^{1}$, and periods differ among species and locations. To remove covariate effects of precipitation and radiation on leaf unfolding, we applied a partial correlation analysis to determine the optimal length of the preseason for each species at each $\operatorname{site}^{30}$. The optimal preseason for each species at each station was defined as the period (with 15-day steps) before the mean leaf unfolding date for which the partial correlation coefficient between leaf unfolding and air temperature was highest during 1980-2013. Using a similar method, we also defined preseason for two 15-year periods (e.g., 1980-1994, 1999-2013) to further assess the robustness of the inferred decline of apparent temperature sensitivity of leaf unfolding over the last three decades (Extended Data Fig. 3a-c).

Linear regression analyses (using both ordinary least squares and reduced major axis regressions) of the dates of leaf unfolding against mean air temperature over the preseason were performed for each species at each site during the three study periods: 1980-2013 (minimum 15-year records required per site), 1980-1994, and 1999-2013 (minimum 7-year records required per site, satisfied simultaneously for the two latter study periods). Similar results, i.e. significant decreases in $\mathrm{S}_{\mathrm{T}}$, were observed using reduced major axis regression method (Extended Data Fig. 5b), we therefore only present the results using ordinary least squares method. The regression coefficient was defined as the apparent temperature sensitivity of leaf unfolding $\left(\mathrm{S}_{\mathrm{T}}\right)$ that reflects the change 
1 in leaf unfolding date per unit increase in mean temperature during the preseason. This is not the

2 actual_physiological sensitivity to temperature, given that other climate-related variables, such

3 as chilling, photoperiod, solar radiation and precipitation, also co-determine the leaf unfolding

4 process and determine the emerging $\mathrm{S}_{\mathrm{T}}$ value diagnosed from the preseason temperature ${ }^{8,12,22}$.

5 The mean $\mathrm{S}_{\mathrm{T}}$ across all sites was calculated for each and all species for these three periods. The

6 frequency distributions of $\mathrm{S}_{\mathrm{T}}$ across all species and sites for 1980-1994 and 1999-2013 were

7 determined. The differences in mean $\mathrm{S}_{\mathrm{T}}$ during 1999-2013 and 1980-1994 were tested using

8 independent $t$-tests for each and across species.

10 To investigate the effect of the chilling requirement and variance in spring temperature on $\mathrm{S}_{\mathrm{T}}$, we

11 calculated species-specific variances in spring temperature and chilling requirements at each site.

12 The spring temperature variance was calculated as the standard deviation of mean temperature 13 during the preseason. The chilling requirement is normally defined as the length of the period 14 (days or hours) during which temperature remains within a specific range. Most previous studies 15 have reported that temperatures slightly above freezing are most effective in satisfying the 16 chilling requirement ${ }^{31}$ and have suggested that the temperature range between 0 and $5{ }^{\circ} \mathrm{C}$ is the 17 most effective across species. To calculate the chilling requirement, we therefore summed the 18 days when daily temperature was within this range:

$C D_{r e q}(t)=\sum_{t_{0}}^{t_{L F}} 1$ if $\quad 0 \leq T_{t} \leq 5$

where $C D_{\text {req }}$ is the chilling requirement, $t_{L F}$ is the day of leaf unfolding, $T_{t}$ is the daily mean temperature on day $t$, and $t_{0}$ is the start date for chilling accumulation. $t_{0}$ was fixed at 1 November

22 in the year prior to leaf unfolding. We also tested another commonly used temperature threshold, $235^{\circ} \mathrm{C}^{24}$, and included all temperatures below this threshold.

$24 \quad C D_{\text {req }}(t)=\sum_{t_{0}}^{t_{L F}} 1$ if $T_{t} \leq 5$

25 The differences in mean during 1999-2013 and 1980-1994 were tested using independent $t$-tests

26 for each and across species. Ordinary least squares linear regression was applied to determine the 27 temporal change in the chilling requirement for 1980-2013 and to determine the correlation 28 between chilling accumulation and $\mathrm{S}_{\mathrm{T}}$. 


\section{Reference}

31 Menzel, A. et al. European phenological response to climate change matches the warming $4 \quad$ pattern. Global Change Biol. 12, 1969-1976 (2006).

52 Myneni, R. C., Keeling, C. D., Tucker, C. J., Asrar, G. \& Nemani, R. R. Increased plant growth in the northern high latitudes from 1981 to 1991. Nature 386, 698-702 (1997). Peñuelas, J. \& Filella, I. Responses to a warming world. Science 294, 793-795 (2001).

84 Fu, Y. S. H. et al. Recent spring phenology shifts in western Central Europe based on multiscale observations. Global Ecol. Biogeogr. 23, 1255-1263 (2014).

5 Yu, H. Y., Luedeling, E. \& Xu, J. C. Winter and spring warming result in delayed spring phenology on the Tibetan Plateau. Proc. Natl. Acad. Sci. U.S.A 107, 22151-22156 (2010).

6 Chuine, I., Morin, X. \& Bugmann, H. Warming, photoperiods, and tree phenology. Science 329, 277-278 (2010).

7 Fu, Y. S. H., Campioli, M., Deckmyn, G. \& Janssens, I. A. Sensitivity of leaf unfolding to experimental warming in three temperate tree species. Agric. For. Meteorol. 181, 125-132 (2013).

8 Laube, J. et al. Chilling outweighs photoperiod in preventing precocious spring development. Global Change Biol. 20, 170-182 (2014).

9 Chuine, I. Why does phenology drive species distribution? Philos. Trans. R. Soc. London, Ser. B 365, 3149-3160 (2010).

10 Zohner, C. M. \& Renner, S. S. Common garden comparison of the leaf-out phenology of woody species from different native climates, combined with herbarium records, forecasts long-term change. Ecol. Lett. 17, 1016-1025 (2014).

11 Peñuelas, J., Rutishauser, T. \& Filella, I. Phenology feedbacks on climate change. Science 324, 887-888 (2009).

12 Richardson, A. D. et al. Climate change, phenology, and phenological control of vegetation feedbacks to the climate system. Agric. For. Meteorol. 169, 156-173 (2013). IPCC. Climate Change 2014: Impacts, Adaptation, and Vulnerability. Part A: Global and Sectoral Aspects. Contribution of Working Group II to the Fifth Assessment Report of the Intergovernmental Panel on Climate Change [Field, C.B., V.R. Barros, D.J. Dokken, K.J. 

Mach, M.D. Mastrandrea, T.E. Bilir, M. Chatterjee, K.L. Ebi, Y.O. Estrada, R.C. Genova, B. Girma, E.S. Kissel, A.N. Levy, S. MacCracken, P.R. Mastrandrea, and L.L. White (eds.)]. (Cambridge University Press, 2014).

4 Piao, S. et al. Leaf onset in the northern hemisphere triggered by daytime temperature. Nat. Commun. 6, 6911 (2015).

15 Way, D. A. \& Montgomery, R. A. Photoperiod constraints on tree phenology, performance and migration in a warming world. Plant Cell Environ. 38, 1725-1736 (2014).

6 Wolkovich, E. M. et al. Warming experiments underpredict plant phenological responses to climate change. Nature $\mathbf{4 8 5}$, 494-497 (2012).

17 Vitasse, Y. Ontogenic changes rather than difference in temperature cause understory trees to leaf out earlier. New Phytol. 198, 149-155 (2013).

18 Beer, C. et al. Harmonized European long-term climate data for assessing the effect of changing temporal variability on land-atmosphere $\mathrm{CO}_{2}$ fluxes. J. Clim. 27, 4815-4834 (2014).

19 Badeck, F. W. et al. Responses of spring phenology to climate change. New Phytol. 162, 295-309 (2004).

20 Wang, T. et al. The influence of local spring temperature variance on temperature sensitivity of spring phenology. Global Change Biol. 20, 1473-1480 (2014).

21 Vitasse, Y., Lenz, A. \& Körner, C. The interaction between freezing tolerance and phenology in temperate deciduous trees. Front. Plant Sci. 5, 541 (2014).

22 Körner, C. \& Basler, D. Phenology under global warming. Science 327, 1461-1462 (2010).

23 Basler, D. \& Körner, C. Photoperiod sensitivity of bud burst in 14 temperate forest tree species. Agric. For. Meteorol. 165, 73-81 (2012).

24 Hunter, A. F. \& Lechowicz, M. J. Predicting the timing of budburst in temperate trees. $J$. Appl. Ecol. 29, 597-604 (1992).

25 Harrington, C. A., Gould, P. J. \& St Clair, J. B. Modeling the effects of winter environment on dormancy release of Douglas-fir. Forest Ecol. Manag. 259, 798-808 (2010). 
126 Kimball, J. S. et al. Satellite radar remote sensing of seasonal growing seasons for boreal and sub-alpine evergreen forests. Remote Sens. Environ 90, 243-258 (2004).

327 Piao, S. et al. Growing season extension and its impact on terrestrial carbon cycle in the Northern Hemisphere over the past 2 decades. Glob. Biogeochem. Cycles 21, GB3018 (2007).

628 White, M. A., Running, S. W. \& Thornton, P. E. The impact of growing-season length variability on carbon assimilation and evapotranspiration over 88 years in the eastern US deciduous forest. Int. J. Biometeorol 42, 139-145 (1999).

929 Rahmstorf, S. \& Coumou, D. Increase of extreme events in a warming world. Proc. Natl. Acad. Sci. U.S.A 108, 17905-17909 (2011).

$30 \mathrm{Fu}, \mathrm{Y}$. S. H. et al. Variation in leaf flushing date influences autumnal senescence and next year's flushing date in two temperate tree species. Proc. Natl. Acad. Sci. U.S.A 111, 73557360 (2014).

Supplementary Information is linked to the online version of the paper at www.nature.com/nature.

\section{Acknowledgments}

This study was supported by the National Natural Science Foundation of China (41125004 and 31321061), and National Youth Top-notch Talent Support Program in China. Yongshuo H. Fu is supported by an FWO Pegasus Marie Curie Fellowship. Ivan A. Janssens, Philippe Ciais and Josep Peñuelas acknowledge support from the European Research Council through Synergy grant ERC-2013-SyG-610028 AMBALANCE-P” and Annette Menzel acknowledges support through the (FP7/2007-2013)/ERC grant 282250 -E3-Extreme Event Ecology”. Ivan A. Janssens acknowledges support from the University of Antwerp Centre of Excellence -GCE". We thank 
1 manuscript. The authors gratefully acknowledge all members of the PEP725 project for providing

2 the phenological data.

4 Author contributions

S.L.P., Y.H.F. and I.A.J. designed the research; H.F.Z., Y.H.F., M. P., S.S.P. and G.Y.Z performed the analysis; Y.H.F., S.L.P. and I.A.J. drafted the paper; and all authors contributed to the interpretation of the results and to the text.

Author Information

Reprints and permission information are available at www.nature.com/reprints. The authors have no competing financial interests. Correspondence and requests for materials should be addressed to S.L.P. (slpiao@pku.edu.cn).

Figure Legends

Figure 1. Changes of apparent temperature sensitivity of leaf unfolding $\left(S_{T}\right.$, advances in days per degree Celsius warming) over time. (a) Species-specific $\mathbf{S}_{\mathbf{T}}$ and its standard deviation (in brackets) across all sites in three periods and its difference between 1999-2013 and 19801994. The $\mathrm{S}_{\mathrm{T}}$ was determined using the preseason fixed at the time period 1980-2013 and using ordinary least squares linear regression. The colour scale indicates magnitude of $\mathrm{S}_{\mathrm{T}}$. AG, alder

19 (Alnus glutinosa); BP, silver birch (Betula pendula); AH, horse chestnut (Aesculus hippocastanum); FS, beech (Fagus sylvatica); TC, lime (Tilia cordata); QR, oak (Quercus robur); FE, ash (Fraxinus excelsior). The number of sites for each species are in brackets under the species name. (b) The distribution of $\mathrm{S}_{\mathrm{T}}$ across all species and sites in two different periods and the mean $\mathrm{S}_{\mathrm{T}}$ and standard deviations (in brackets). The asterisk indicates a significant difference of $\mathrm{S}_{\mathrm{T}}$ between the two periods at $P<0.05$. (c) Temporal change of $\mathrm{S}_{\mathrm{T}}$ for each and all species across all sites with a 15-year moving window from 1980 to 2013. The black line indicates the average across all species, and the grey area indicates one standard deviation either

27 side of the mean. The dotted line indicates the linear regression. 
2 Figure 2. Changes of chilling and spring temperature variation (Tstd) between 1980-1994

3 and 1999-2013. Species-specific Tstd (a) and chilling accumulation (b) across all sites over two 4 periods, 1980-1994 and 1999-2013. The Tstd was calculated as the standard deviation of mean 5 spring temperature during the preseason over these two periods. The preseason was defined as the

6 period before leaf unfolding for which the correlation coefficient between leaf unfolding and 7 temperature was highest. The chilling accumulation was calculated as chilling days when daily 8 temperature was between 0 and $5{ }^{\circ} \mathrm{C}$ from 1 November to the average date of leaf unfolding. The 9 asterisks indicate significant differences at $P<0.05$.

Figure 3. Changes of modeled apparent temperature sensitivity of leaf unfolding $\left(S_{T}\right.$, advances in days per degree Celsius warming). As in Fig. 1a, panels a-c show the modelled species-specific $\mathrm{S}_{\mathrm{T}}$, including the standard deviations (in brackets), across all sites during three periods and its difference between 1999-2013 and 1980-1994. (a) Sequential model, (b) Parallel model and (c) Unified model. As in Fig. 1c, panels d-f show the modelled temporal change of $\mathrm{S}_{\mathrm{T}}$ for each and all species across all sites with a 15-year moving window from 1980 to 2013. (d) Sequential model, (e) Parallel model and (f) Unified model. The model performance is provided in $(\mathrm{g})$. The $\mathrm{S}_{\mathrm{T}}$ was determined using the preseason fixed at the time period 1980-2013 and using ordinary least squares linear regression. The colour scale indicates magnitude of $\mathrm{S}_{\mathrm{T}}$. RMSE, root mean square error; AG, alder (Alnus glutinosa); BP, silver birch (Betula pendula); AH, horse chestnut (Aesculus hippocastanum); FS, beech (Fagus sylvatica); TC, lime (Tilia cordata); QR, oak (Quercus robur); FE, ash (Fraxinus excelsior). The number of sites for each species are in brackets under the species name.

Extended Data Figure Legends:

26 Extended Data Figure 1. The distribution of the sites. The data were obtained from the Pan

27 European Phenology network (http://www.pep725.eu/). 

optimal preseason was defined as the period before leaf unfolding for which the correlation coefficient between leaf unfolding and temperature was highest. The numbers in the brackets are the mean dates of leaf unfolding across all sites.

Extended Data Figure 3. Changes of apparent temperature sensitivity of leaf unfolding $\left(S_{T}\right.$, advances in days per degree Celsius warming) between 1980-1994 and 1999-2013. Same as Fig. 1, but the $\mathrm{S}_{\mathrm{T}}$ was calculated based on the preseason that was determined either in the time period 1980-1994 (b) or in 1999-2013 (c). The differences in preseason lengths are provided for each and all species (a), and the figures above bars are the mean absolute preseason difference between two periods. For $\mathrm{b}$ and $\mathrm{c}$, species-specific $\mathrm{S}_{\mathrm{T}}$ and its standard deviation (in brackets) across all sites in three periods and its difference between 1999-2013 and 1980-1994. The colour scale indicates magnitude of $\mathrm{S}_{\mathrm{T}}$. AG, Alnus glutinosa; BP, Betula pendula; AH, Aesculus hippocastanum; FS, Fagus sylvatica; TC, Tilia cordata; QR, Quercus robur; FE, Fraxinus excelsior. The number of sites for each species are in brackets under the species name. (d) The distribution of the proportion and corresponding days (e) of the encroachment of phenology dates into the preseason temperature that the preseason was determined on the period 1980-2013. The proportion was defined as the difference of the mean leaf unfolding dates (diff MSOS) between the period 1999-2013 and 1980-2013 (which is the end date of the preseason temperature that was used to calculate the $\mathrm{S}_{\mathrm{T}}$ ) divided by the preseason length in days. The mean values and its standard deviation (in brackets) are provided for each and all species.

Extended Data Figure 4. The distribution of partial correlation coefficients between preseason temperature and leaf unfolding dates over the time period 1980- 2013. The mean (and standard deviation: STD) of the correlation coefficients across all species and sites are provided. The percentages of negative correlations and statistically significant negative correlations $(\mathrm{Neg}(\mathrm{Sig}))$ are also provided.

Extended Data Figure 5. Changes of apparent temperature sensitivity of leaf unfolding $\left(\mathrm{S}_{\mathrm{T}}\right.$, advances in days per degree Celsius warming) determined by different methods. The $S_{T}$ 

regression (b), or were calculated based on another climate forcing dataset (CRU-NCEP v5, c).

2 Species-specific $\mathrm{S}_{\mathrm{T}}$ and its standard deviation (in brackets) across all sites in three periods and the 3 difference two study periods are provided. The colour scale indicates magnitude of $\mathrm{S}_{\mathrm{T}}$. AG, alder

4 (Alnus glutinosa); BP, silver birch (Betula pendula); AH, horse chestnut (Aesculus 5 hippocastanum); FS, beech (Fagus sylvatica); TC, lime (Tilia cordata); QR, oak (Quercus 6 robur); FE, ash (Fraxinus excelsior). The number under the species name is the number of sites.

7 The histograms show the distribution of $\mathrm{S}_{\mathrm{T}}$ across all species and sites in two different periods

8 and the mean $\mathrm{S}_{\mathrm{T}}$ and standard deviations (in brackets). The asterisk indicates a significant 9 difference of $\mathrm{S}_{\mathrm{T}}$ between the two periods at $P<0.05$.

Extended Data Figure 6. Changes of apparent temperature sensitivity of leaf unfolding $\left(S_{T}\right.$, advances in days per degree Celsius warming) over time. Same as Fig. 1c, but temporal change of $\mathrm{S}_{\mathrm{T}}$ with 10-year moving windows from 1980 to 2013. The $\mathrm{S}_{\mathrm{T}}$ was calculated using simple linear regression. The black line indicates the average across all species, and the grey area indicates one standard deviation either side of the mean. The dotted line indicates the linear regression.

Extended Data Figure 7. The differences in climatology over the preseason. The fluctuations in mean daily temperature (left panels) and diurnal variation temperature (Tmax - Tmin, right panels) over the preseason across all sites during the time period 1980-1994 and 1999-2013 in three MAT groups, i.e. (top panels) $6-8^{\circ} \mathrm{C}$, (middle panels) $8-10^{\circ} \mathrm{C}$ and (bottom panels) $10-12^{\circ} \mathrm{C}$. The preseason was determined over the period 1980-2013.

Extended Data Figure 8. Spatial difference in apparent temperature sensitivity of leaf unfolding $\left(S_{T}\right.$, advances in days per degree Celsius warming) reduction. The difference of $S_{T}$

23 for each species and across all species studied between two time periods, 1999-2014 and 19801994, at different latitudes (bin: $0.5^{\circ}$ ) and chilling conditions (bin: two chilling days). The colour scales indicate the differences of $\mathrm{S}_{\mathrm{T}}$ between the two periods.

Extended Data Figure 9. Changes in chilling accumulation and modeled correlation between chilling and apparent temperature sensitivity of leaf unfolding $\left(\mathrm{S}_{\mathrm{T}}\right.$, advances in 
1 days per degree Celsius warming). (a) Chilling accumulation for each and all species with 15-

2 year moving windows from 1980 to 2013. The chilling accumulation was calculated as chilling

3 days when daily temperature was between 0 and $5{ }^{\circ} \mathrm{C}$ from 1 November to the average date of

4 leaf unfolding. The black line indicates the average across all species, and the grey area indicates

5 one standard deviation either side of the mean. The dotted line indicates the linear regression. (b)

6 Same as Fig. 2b, but chilling accumulation was calculated as chilling days when daily

7 temperature was below $5^{\circ} \mathrm{C}$ from 1 November to the average date of leaf unfolding. The asterisks

8 indicate significant differences at $P<0.05$. (c) The modelled (Unified model) $\mathrm{S}_{\mathrm{T}}$ under different

9 artificial winter warming conditions. The temperature in winter, defined as the period from the 1

10 November to 31 January, was warmed by $+1{ }^{\circ} \mathrm{C}$ to $+5^{\circ} \mathrm{C}$ over the period $1980-2013$. The points

11 with most chilling days indicate the real winter temperatures, and each of the other points

12 indicate one winter warming treatment. The lines indicate simple linear regressions.

13 Extended Data Figure 10. Changes in apparent temperature sensitivity of leaf unfolding $14\left(\mathbf{S}_{\mathrm{T}}\right.$, advances in days per degree Celsius warming) between years with more or less chilling.

$15 \mathrm{~S}_{\mathrm{T}}$ for years with (a) less chilling and (b) more chilling with a 20-year moving window for 1980-

16 2013. For each 20-year series, we divided the 20 years into two groups based on the mean

17 chilling accumulation (Chilling was accumulated when daily temperature within the temperature

18 range between $0^{\circ} \mathrm{C}$ and $5^{\circ} \mathrm{C}$ from $1^{\text {st }}$ November to the day of leaf unfolding). The 10 years with

19 chilling higher than the overall mean were defined as more chilling, and the other 10 years were

20 defined as less chilling. The black lines indicate the average across all species, and the grey area

21 indicates one standard deviation either side of the mean. The dotted lines are the linear

22 regressions. (c) Chilling accumulation for years with less chilling (red line) and more chilling

23 (blue line) with a 20-year moving window for 1980-2013. (d) The mean radiation sum over the

24 preseason for years with less chilling (red line) and more chilling (blue line) with a 20-year

25 moving window for 1980-2013. The preseason was determined over the period 1980-2013. 


\section{Supplementary information}

2

3 To test the hypothesis that the observed decline in $\mathrm{S}_{\mathrm{T}}$ is in fact a response to the declining 4 chilling, we applied three commonly used chilling-based phenology models, i.e. the 5 Sequential, Parallel and Unified models, to simulate the leaf unfolding dates. We then 6 calculated the $\mathrm{S}_{\mathrm{T}}$ using the same method as for the observations. We chose a simulated 7 annealing method to fit the models based on the observation over the period 1980-2013. The 8 details of these three models are described below. In the models, the effects of the forcing and 9 chilling temperatures are accounted for by calculating (daily) rates of forcing $\left(R_{f}\right)$ and chilling $\left(R_{c}\right)$, which are functions of the daily air temperature $(T)$. These functions differ between models. $R_{f}$ and $R_{c}$ determine the rates of change of the states of forcing $\left(S_{f}\right)$ and chilling $\left(S_{c}\right)$, respectively:

$$
\begin{gathered}
S_{f}(D)=\sum_{t=t_{f}}^{D} R_{f}(T) \\
S_{c}(D)=\sum_{t=t_{c}}^{D} R_{c}(T)
\end{gathered}
$$

where $t_{l f}$ and $t_{l c}$ are the initial days of the forcing and chilling periods, respectively, and $D$ is the day of the year. Leaf unfolding is triggered when $S_{f}$ reaches a forcing threshold $F^{*}$, whereas in the Sequential and the Parallel models, the start of quiescence (the forcing period) is triggered when $S_{c}$ reaches the chilling threshold $C^{*}$.

$$
\text { if } S_{f}(D) \geq F^{*} \quad \text { then leaf unfolding induction is completed }
$$

$$
\text { if } S_{c}(D) \geq C^{*} \quad \text { then dormancy is completed }
$$

\section{Sequential model (SM) $)^{32,33}$}

$S M$ starts to accumulate warmth units when a sufficient amount of chilling has occurred (Eq. 4). In $S M$, we fixed $t_{l c}$ on 1 November. As in the previous applications of $S M$, we defined $R_{c}$ as a triangular function of $T^{32,33}$ : 


$$
R_{c}(D)= \begin{cases}0 & \text { if } T(D) \leq T_{\min } \\ \frac{\mathrm{T}-\mathrm{T}_{\min }}{\mathrm{T}_{\mathrm{opt}}-\mathrm{T}_{\min }} & \text { if } T_{\min }<T(D) \leq T_{o p t} \\ \frac{\mathrm{T}-\mathrm{T}_{\max }}{\mathrm{T}_{\mathrm{opt}}-\mathrm{T}_{\max }} & \text { if } T_{\text {opt }}<T(D) \leq T_{\max } \\ 0 & \text { if } T \geq(D) T_{\max }\end{cases}
$$

2 where $T_{\min }, T_{\max }$ and $T_{\text {opt }}$ are the minimum, maximum and optimum temperature for the 3 chilling period. $R_{f}$ is calculated with a similar sigmoid function as:

$$
R_{f}(D)=\left\{\begin{array}{cll}
0 & \text { if } & S_{c}<C^{*} \\
\frac{a}{1+e^{-b(T-c)}} & \text { if } & S_{c} \geq C^{*}
\end{array}\right.
$$

\section{$5 \quad$ Parallel model (PM) ${ }^{32,33,34}$}

$6 \quad P M$ assumes that forcing temperature can affect leaf unfolding even during the chilling. As

7 for $\mathrm{SM}$, we fixed $\mathrm{t}_{1 \mathrm{c}}$ and $\mathrm{t}_{1 \mathrm{f}}$ on 1 November. $R_{c}$ is calculated as in $S M$, whereas $R_{f}$ is calculated

8 with the following equation, a modification of Eq. 6 of SM:

9

$$
R_{f}(D)=\left\{\begin{array}{ccc}
0 & \text { if } & D<t_{0} \\
k \frac{a}{1+e^{-b(T-c)}} \text { if } & D \geq t_{0}
\end{array} \text { and } \quad k= \begin{cases}K_{m}+\frac{1-K_{m}}{C^{*}} S_{c} & \text { if } S_{c}<C^{*} \\
1 & \text { if } S_{c} \geq C^{*}\end{cases}\right.
$$

where $K_{m}$ is a model parameter. $P M$ has one more parameter $\left(K_{m}\right)$ than $S M$.

\section{Unified model $(U M)^{35}$}

$U M$ combines features of the other models and merges the equations for $R_{c}$ and $R_{f}$ into one sigmoid equation:

$$
\frac{1}{1+e^{a(T-c)^{2}+b(T-c)}}= \begin{cases}R_{C}(\mathrm{D}) & \text { if } \mathrm{a}=C_{a} \text { and } \mathrm{b}=C_{b} \text { and } \mathrm{c}=C_{c} \\ R_{f}(\mathrm{D}) & \text { if } \mathrm{a}=0 \quad \text { and } \mathrm{b}=F_{b} \text { and } \mathrm{c}=F_{c}\end{cases}
$$

where $C_{a}, C_{b}$ and $C_{\mathrm{c}}$ are chilling-rate parameters and $F_{b}$ and $F_{c}$ are forcing-rate parameters. In $U M, t_{l c}$ is set to be 1 September. The forcing units start to accumulate when a sufficient amount of chilling has occurred $\left(C^{*}\right)$, and $F^{*}$ is calculated with an exponential function of $R_{c}$ from $t_{1 c}$ to $t_{2 c}$ : 
$1 \quad$ where $k, w$ and $t_{2 c}$ are model parameters.

\section{Parameter estimation}

3 All three models were fitted using observed leaf unfolding dates for each site and species for 4 the period 1980-2013, for a total of 5,472 (sites*species) parameter estimates. Parameters 5 were adjusted by minimizing the root mean square error (RMSE; Eq. 10) between observed 6 and modelled leaf unfolding dates:

$$
R M S E=\sqrt{\frac{\sum_{i=1}^{n}\left(X_{o b s, i}-X_{m o d, i}\right)^{2}}{n}}
$$

7 where $X_{o b s, i}$ is the observed value, $X_{m o d, i}$ is the modelled value of the observation $i$ and $n$ is the 8 number of observations. Following the study of Chuine et $a l^{36}$, we calibrated the models 9 using a simulated annealling method. The simulated annealling refers to thermodynamic principles where the objective function, here the RMSE, is considered as an energy function of a cooling and crystallizing molten metal. An artificial temperature is introduced and gradually lowered until it reaches a global minimum. At each iteration, the algorithm explores the range of possible states of the system by changing parameter values according to a generalized Metropolis algorithm acceptance probability. Simulated annealling methods are less affected by local minima than gradient methods ${ }^{37}$, but the number of local minima of the RMSE function of phenological models is high. We thus performed thousands of global searches with few iterations and random initial parameters followed by a global search with more iterations and starting at the best result yet obtained for each optimization ${ }^{35}$. The range of variation for each parameter was prescribed according to previously published results of model optimization ${ }^{35,36,38}$.

\section{References:}

32 Hänninen, H., Modelling bud dormancy release in trees from cool and temperate regions. Acta For. Fenn 213, 1- 47 (1990).

33 Kramer, K., Selecting a model to predict the onset of growth of Fagus-Sylvatica. $J$. Appl. Ecol. 31, 172-181 (1994). 
134 Landsberg, J.J., Apple fruit bud development and growth - analysis and an empirical model. Ann. Bot. 38, 1013-1023 (1974).

335 Chuine, I., A unified model for budburst of trees. J. Theor. Biol. 207, 337-47 (2000).

436 Chuine, I., Cour, P. and Rousseau. D. D., Fitting models predicting dates of flowering of temperate-zone trees using simulated annealing. Plant Cell Environ 21, 455-66 (1998).

737 Tsallis, C., \& Stariolo, D.A., Generalized simulated annealing. Physica A 406, 395406 (1996).

938 Linkosalo, T, Lappalainen, H.K. and Hari, P., A Comparison of phenological models of leaf bud burst and flowering of boreal trees using independent observations. Tree Physiol. 28, 1873-82 (2008). 
Extended Data Figure 1.

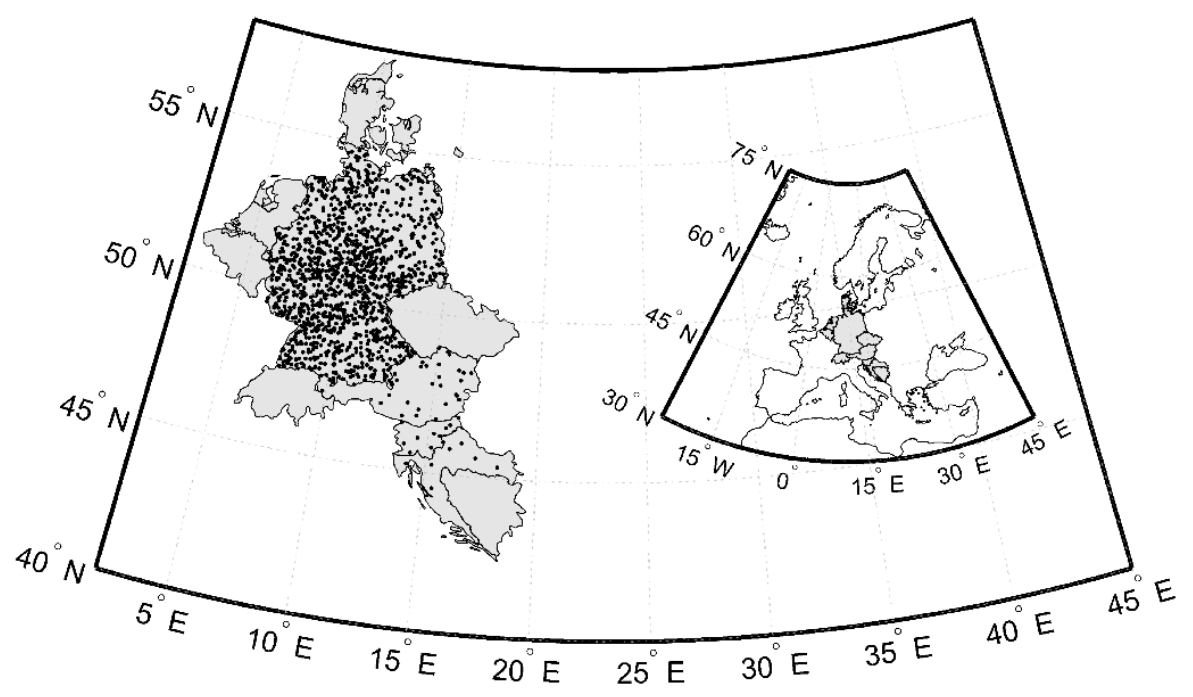


Extended Data Figure 2.

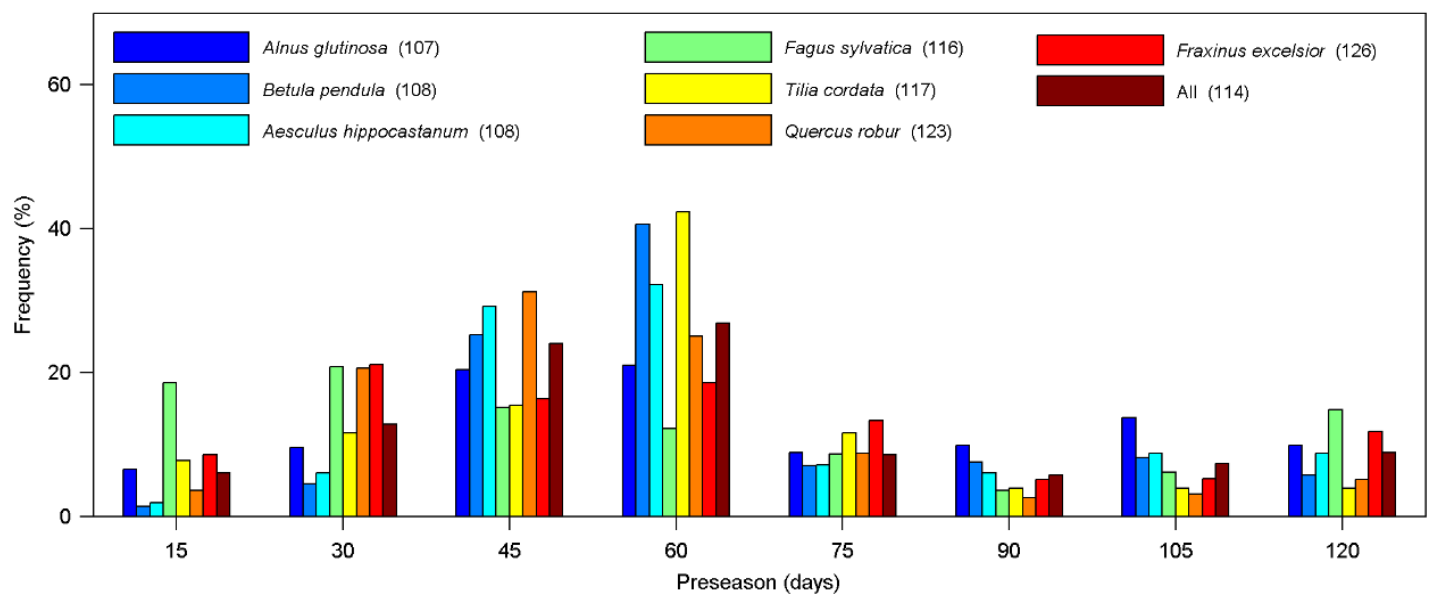




\section{Extended Data Figure 3.}
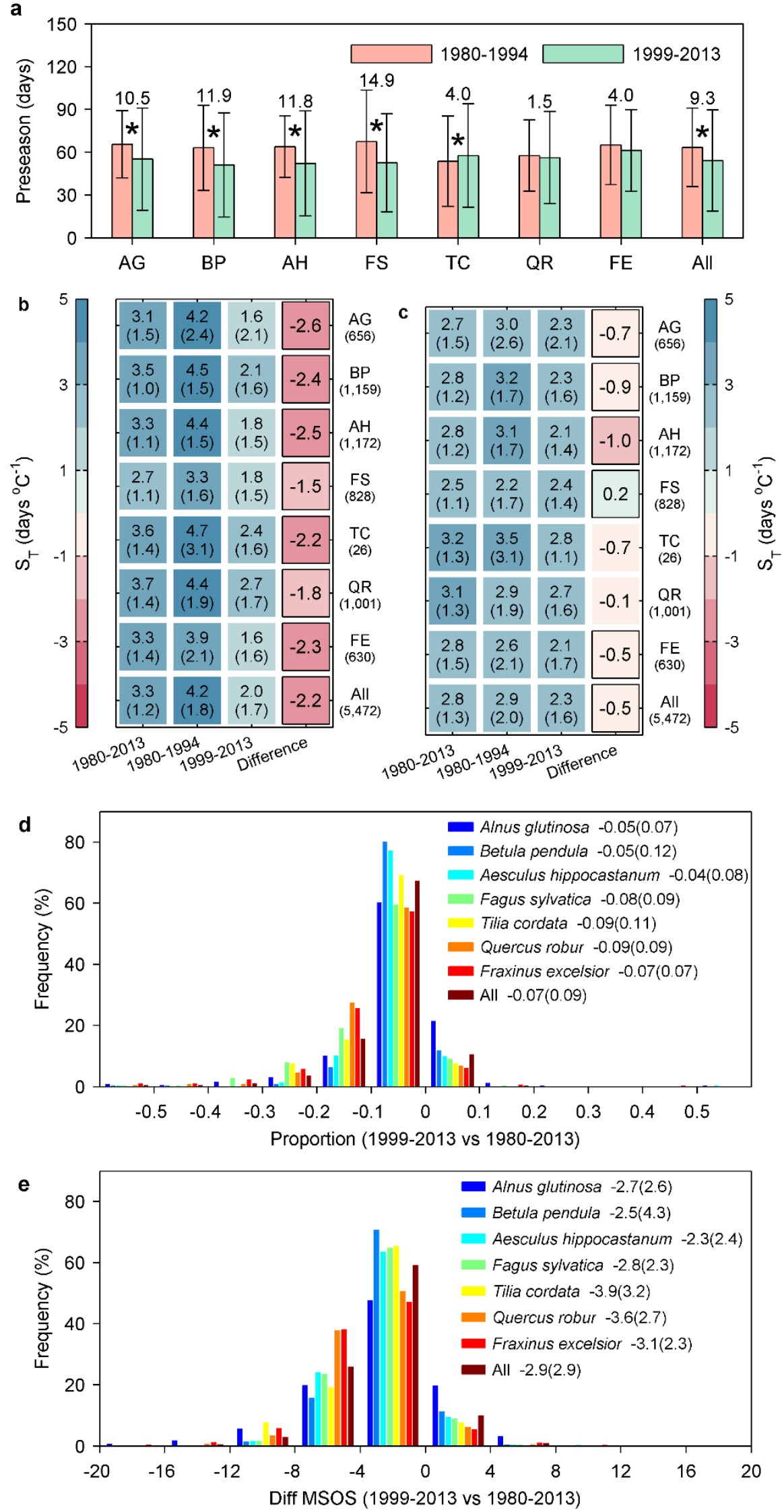
Extended Data Figure 4.

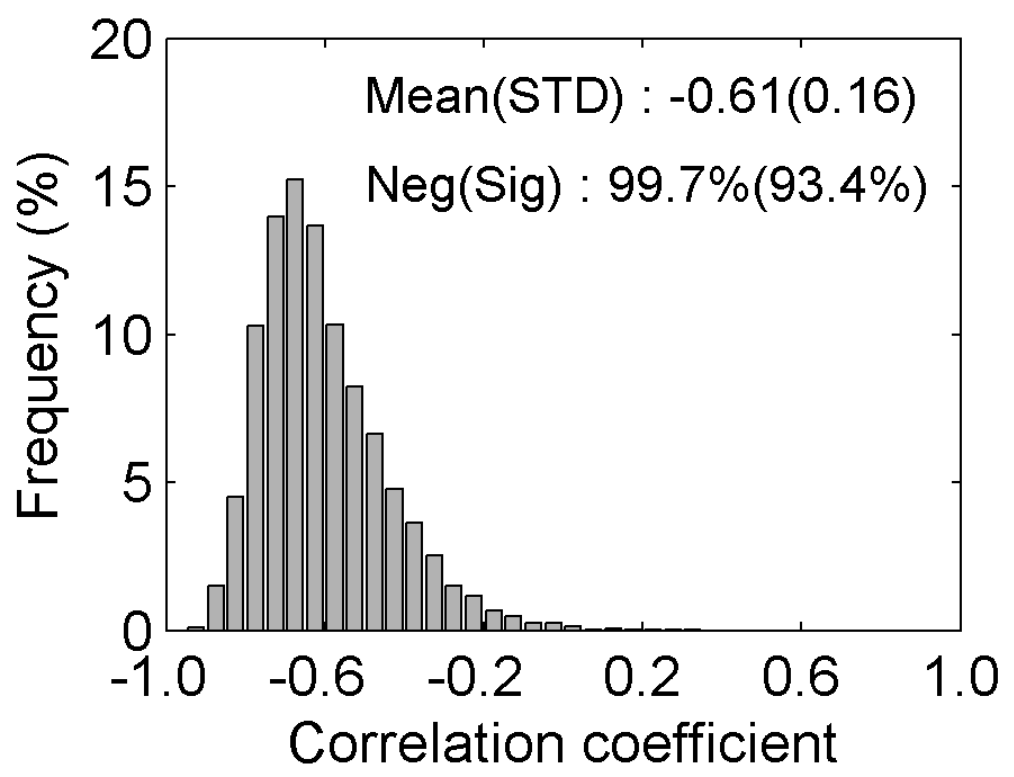




\section{Extended Data Figure 5.}
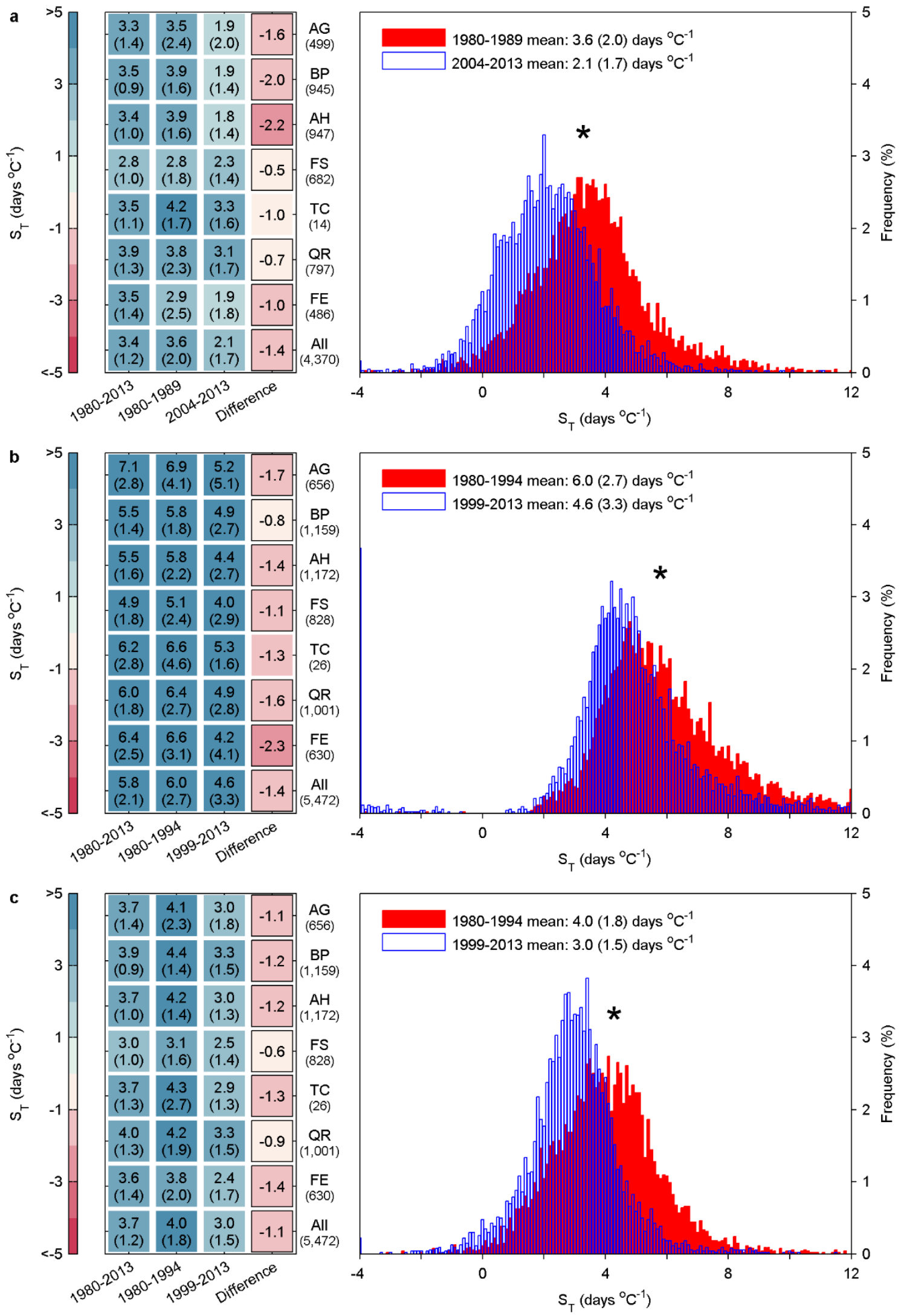


\section{Extended Data Figure 6.}

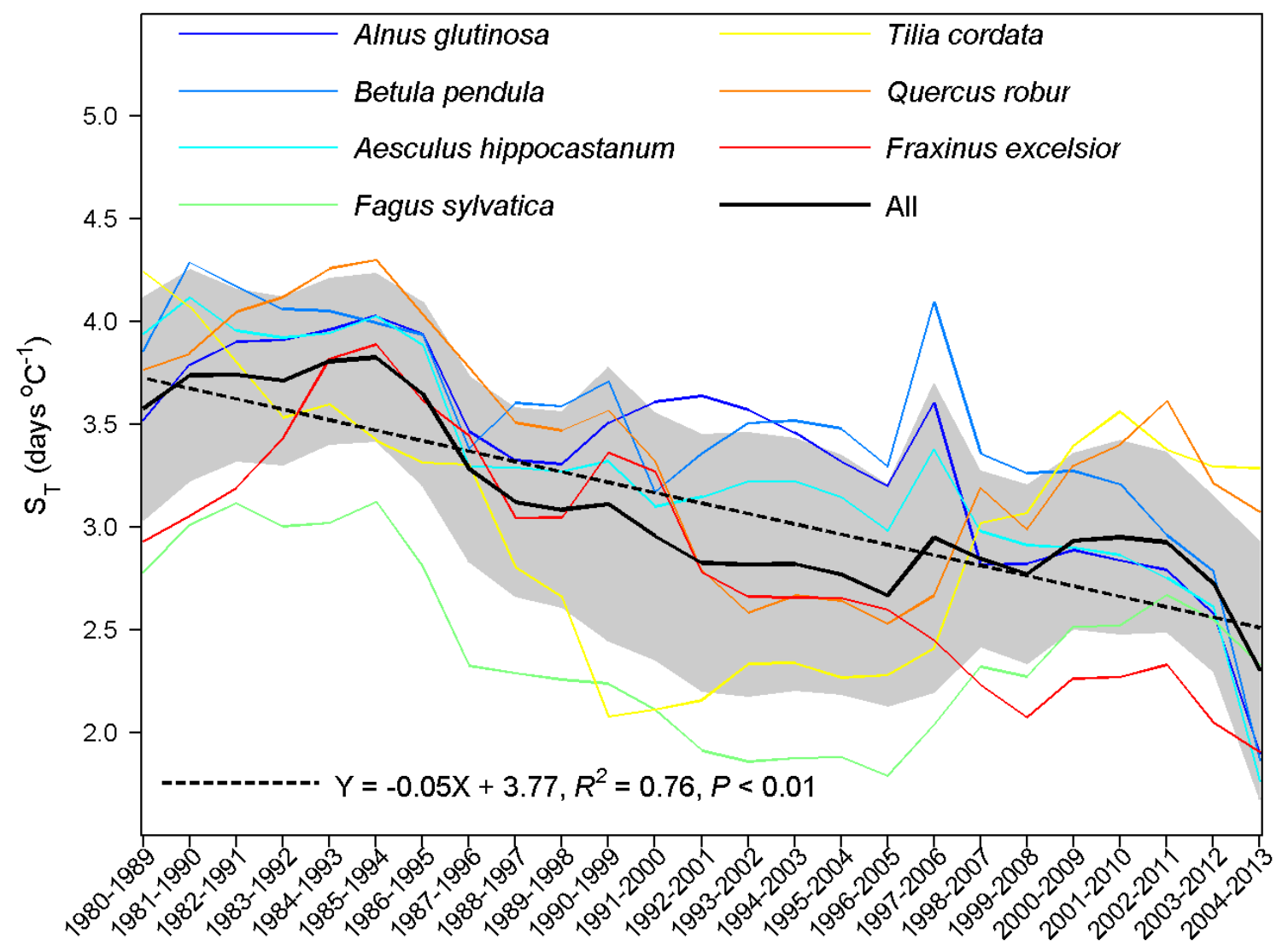

Period 


\section{Extended Data Figure 7.}
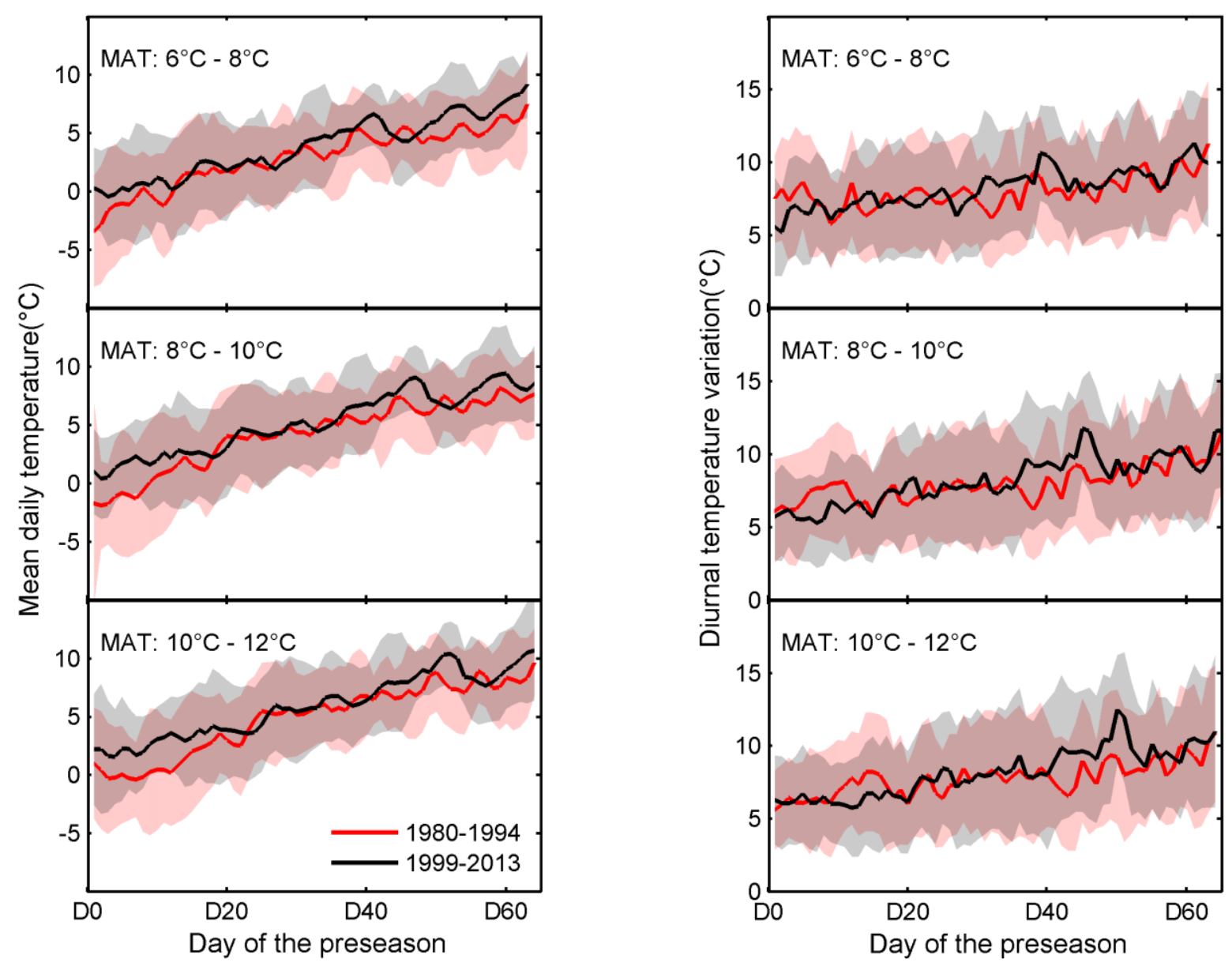
Extended Data Figure 8.

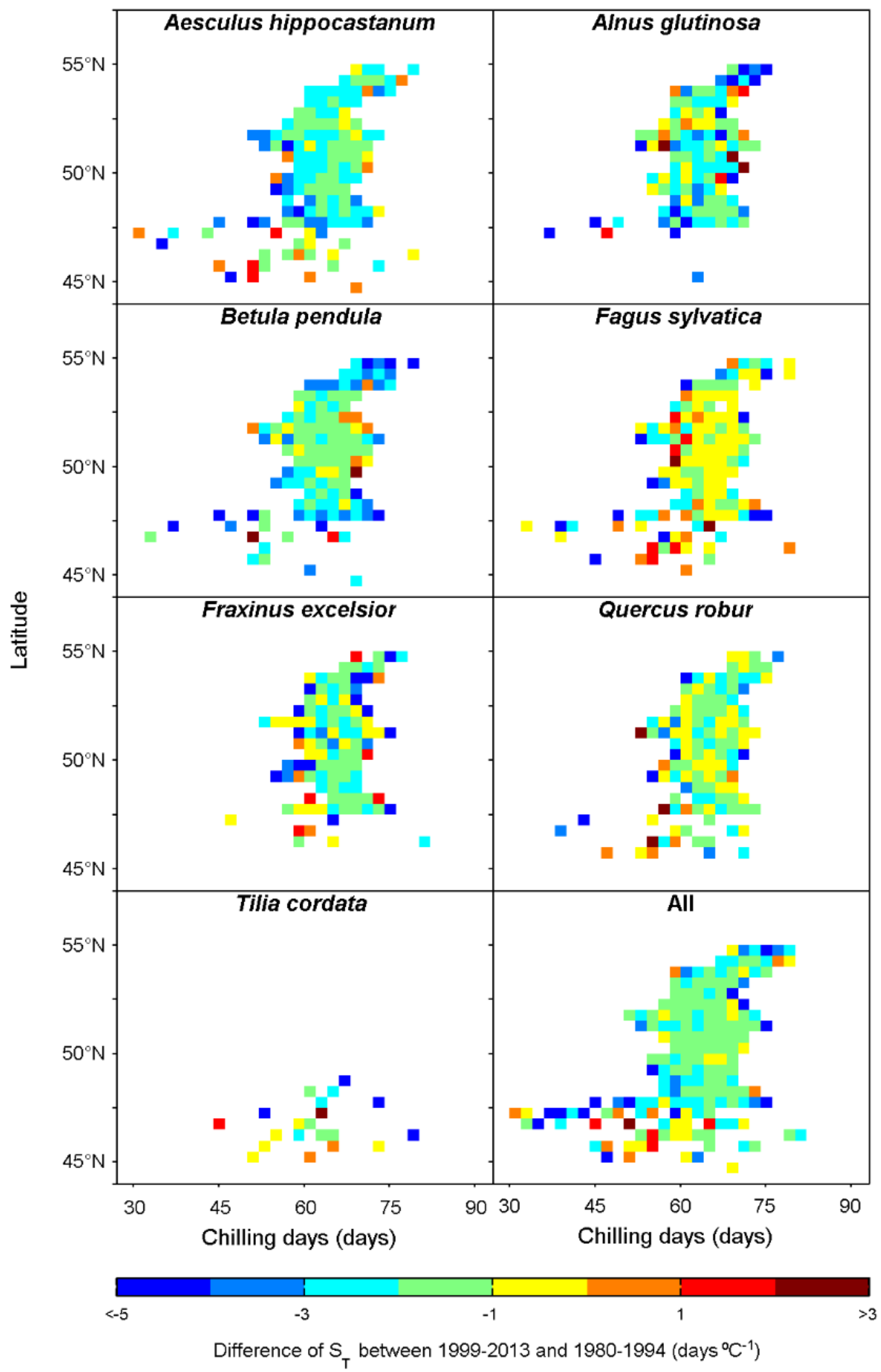




\section{Extended Data Figure 9.}
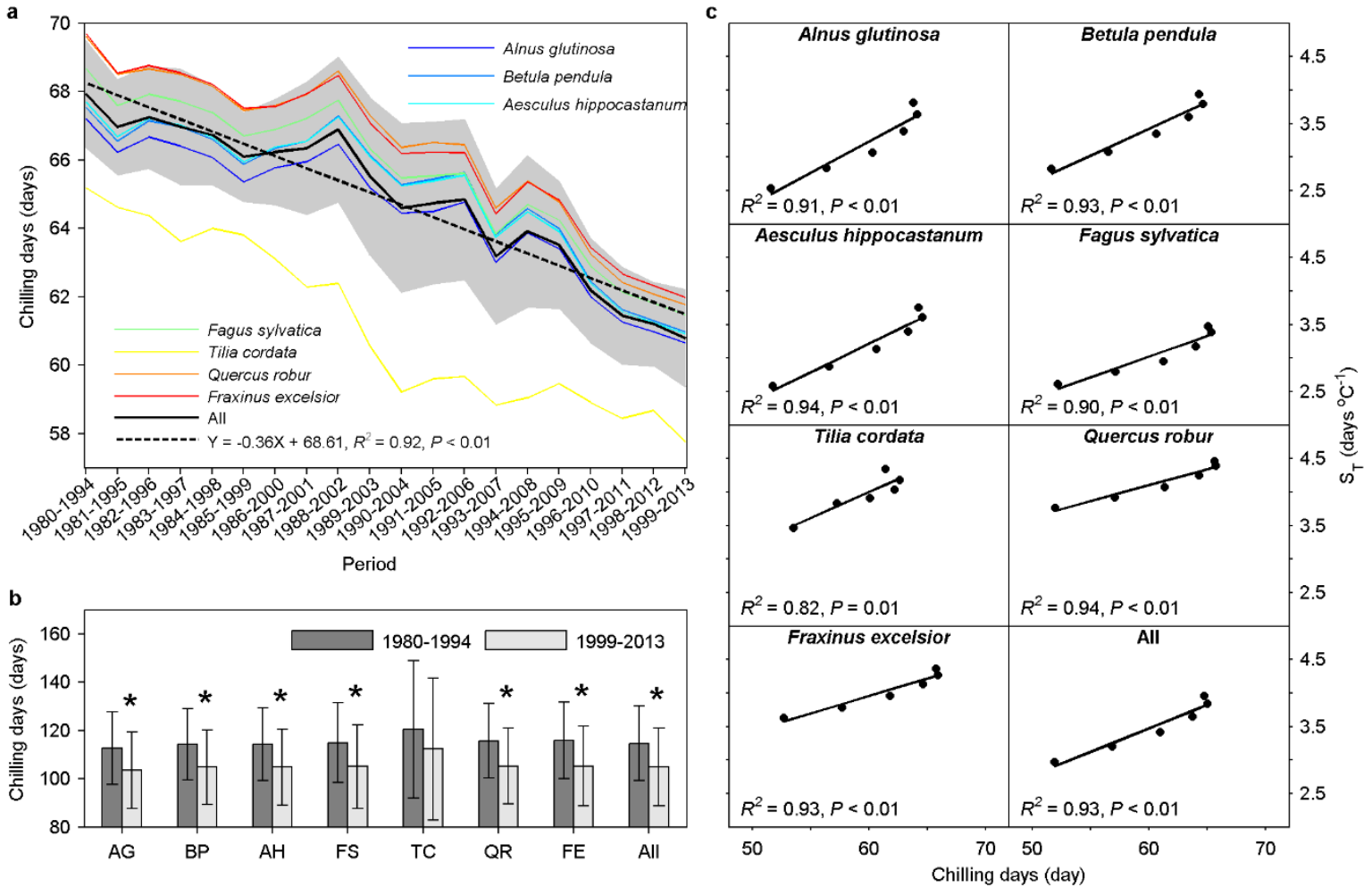


\section{Extended Data Figure 10.}
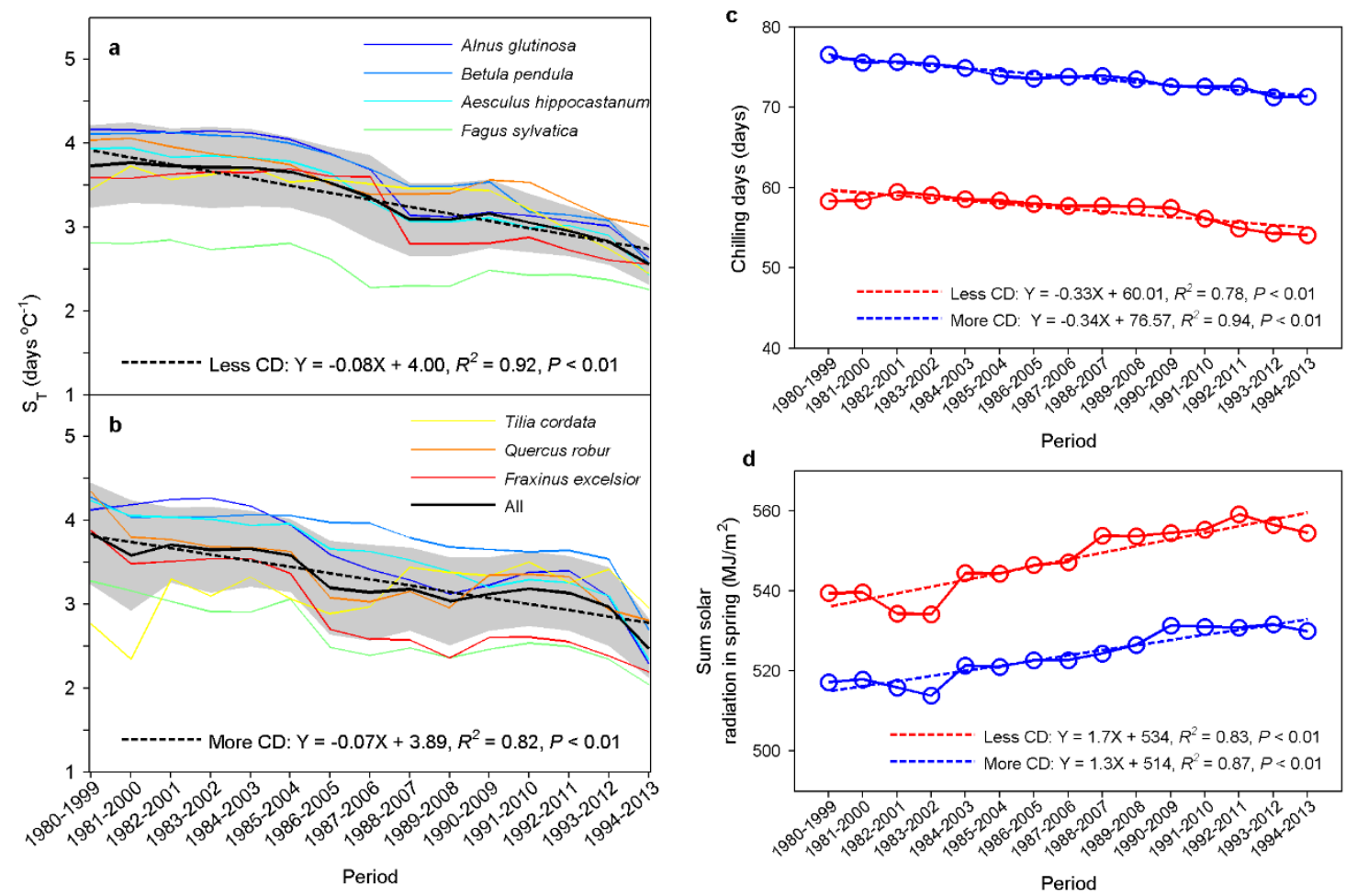